IMAGE

UNAVAILABLE FOR COPYRIGHT REASONS

Venturestar: government funding is planned to cover initial development costs only.

\section{NASA aims high for reusable spacecraft}

Washington. The National Aeronautics and Space Administration (NASA) last week chose the Lockheed-Martin Corporation to build and test a prototype reusable launch vehicle (RLV) that it hopes will dramatically reduce the cost of reaching orbit, beginning around 2005.

The company's VentureStar design beat two other contenders for NASA's X-33 test programme, which will build and fly a halfscale model of the RLV. The vehicle will take off vertically and land horizontally like an aeroplane, and will have no pilot or passengers on board.

NASA has budgeted $\$ 941$ million for building the X-33 and conducting at least 15 test flights in 1999. Lockheed-Martin will contribute a further $\$ 220$ million. After that, however, the government intends to step out and let industry finance, build and operate a working vehicle.

Daniel Goldin, the administrator of NASA, said that the RLV programme aims to cut the price of delivering cargo to orbit to only $\$ 1,000$ a pound, or more than ten times below current costs. Most outside analysts believe this is too optimistic, but they say the RLV has a better chance of being economical than the current space shuttle, which never came close to achieving its original cost projections.

One of the RLV's missions would be to re-supply the international space station. Beyond that, the market for such a vehicle is uncertain. The RLV could have a difficult time competing against single-use rockets for the satellite launch market, and NASA would probably have to make a commitment to buy a large number of flights up front before any private company would be prepared to agree to build an operational version of the launch vehicle.

But the commercial viability of the new vehicle could suffer if it ends up carrying humans. A NASA advisory group last week warned the agency to slow its plans to cut the current shuttle budget, or risk compromising crew safety.

Tony Reichhardt

\title{
German university withdraws doctorate after fraud charge
}

Munich. In what could be the first case of its kind in Germany, a chemistry researcher at the University of Bonn has had his doctorate withdrawn following charges of scientific fraud. But the researcher, Guido Zadel, maintains his innocence, and is likely to challenge the decision in court

Zadel, a former doctoral student at the university's Institute of Organic Chemistry, was awarded his $\mathrm{PhD}$ at the end of 1993. But it was rescinded by the faculty of mathematical and natural sciences earlier this year, two years after he had been caught trying to manipulate the results of a laboratory experiment based on his thesis, which had described a technique for distinguishing 'left-handed' from 'right-handed' molecules.

Through his lawyer, Zadel acknowledges that he committed a single "stupid" act. But he says it was prompted by pressure to obtain positive results, as no group has been able successfully to reproduce his thesis results, which he still defends. The faculty, however, took a less sanguine view. In a 53page report issued in April, it accused him of scientific fraud.

Zadel has claimed to have made a highly significant discovery in the area of 'chiral synthesis', a field of considerable interest to the pharmaceutical industry. So-called chiral molecules are known as enantiomers and exist in two chemically identical forms: lefthanded and right-handed molecules

Pharmaceutical products need to be tested separately for the effects of left- and right-handed molecules, following the tragedy in the early 1960s when women gave birth to children with malformed limbs after being given the sedative thalidomide, which had been contaminated with the wrong enantiomer.

Current testing techniques, however, are expensive and complicated. So when Zadel claimed that the application of a static magnetic field during a chemical reaction would produce an excess of left- or right-handed enantiomers, there was wide interest. He even claims to have discovered that the size of the enantiomer surplus varied according to the size of the magnetic field applied.

On the strength of this unusual yet potentially important result, the German research council, the Deutsche Forschungsgemeinschaft (DFG), extended funding for the project to allow the results to be verified, despite the lack of any theoretical basis for the observation.

The work was published in Angewandte Chemie, the German chemistry journal, in April 1994 (see Angew. Chem. 106, 460; 1994). That, however, was when the trouble started for Zadel and his supervisor Eberhard Breitmaier, a professor at the Institute of Organic Chemistry, because no other research group could reproduce the results.

Zadel was first accused of fraud in May 1994 by two other students of Breitmaier. Claiming now that he was "under pressure", Zadel admitted to mixing some optically active substances with the initial chemicals.

He later revoked this confession, claiming to have been working with a special method that consisted of 'vaccinating' his chemicals with tiny amounts of enantiomers, though not enough to produce the excess later measured. The vaccination might have looked as though he had manipulated the probes, he says.

But Breitmaier, who at first supported Zadel, began to lose faith, and decided to try to catch him out. One of his colleagues set up the experiment again. When the colleague left the room briefly, Zadel replaced the samples with his own enantiomeric mixtures, not knowing that his colleague had hidden half of the test-tubes. Zadel now admits this act was "stupid". The evidence against Zadel seemed incontrovertible and Breitmaier withdrew the paper last July.

But Zadel continues to insist that his results are legitimate and reproducible. Through his lawyer, Johannes Latz, he claims that proof can be found in his laboratory notebooks, which he says were stolen. In addition, he cites successful experiments carried out by a colleague while he was on holiday, as well as experiments performed in front of Breitmaier.

The case has generated considerable interest because allegations of scientific fraud are rare in Germany. Wolfgang Frühwald, head of the DFG, believes this is because German researchers do not have to fight as hard for funding as their colleagues in the United States, where, he says, misconduct is much more frequent.

Frühwald fears that a broader discussion of scientific misconduct might create a climate of mistrust in the community, something he believes should be avoided. Commenting on the Zadel case, Frühwald says the DFG may consider asking the university to return the funds.

But Albin Eser, a director of the Max Planck Institute for Foreign and International Law in Freiburg, says fraud in German science is more widespread than is generally acknowledged. One of Eser's former students, Stefanie Stegemann-Boehl, completed a $\mathrm{PhD}$ thesis comparing fraud in biomedical research in Germany and the United States, and concluded on the basis of extensive interviews that many more cases of fraud in Germany may exist than are made public. 